\title{
Effect on kinematic gait variables of two methods of iner- tial measurement unit sensor attachment to the extremities of horses under controlled conditions of treadmill exercise in sound horses at the walk and trot: A pilot study
}

\author{
Tamara Seghers', Ugo E. Maninchedda' , Beatriz Vidondo², Alessandra Ramseyer' and Antonio M. Cruz ${ }^{\prime}$ \\ 1 Institut suisse de médicine équine, University of Bern, Bern, Switzerland \\ 2 Veterinary Public Health Institute, University of Bern, Bern, Switzerland
}

\begin{abstract}
Summary: The objective of this pilot study was to evaluate the effects of two different methods (straps vs. glued-on) of attaching extremity mounted inertial measurement units (IMUs) to the distal tibia and radius for the evaluation of kinematic variables under controlled conditions of treadmill exercise at the walk and trot. This was performed as a cross over design where three orthopedically sound horses entered two groups: straps and glued-on. Horses were instrumented with eight IMUs at distal radii, tibias and third metacarpal and metatarsal regions. Data were collected three consecutive times during walk and trot on a treadmill at three different times during a time interval of 1 hour. Specifically designed software was used to process the accelerometer and gyroscope signals to obtain spatial and temporal data that described selected kinematic variables predetermined by the system. Repeated-measures ANOVA was used to assess the differences between groups. The results showed the use of straps producing a statistically significant reduction of sagittal range of motion (ROM) on the attached joints and bone segments, namely tarsi, carpi, crus and antebrachium. To conclude the observed reduction of joint's sagittal ROM while variable (0.8 to 12 degrees) should be taken into account when using this system for the evaluation of gait quality profile.
\end{abstract}

Keywords: ROM, IMU, gait evaluation, kinematics, equine, joint angles, attachment method

Citation: Seghers T., Maninchedda U. E., Vidondo B., Ramseyer A., Cruz A. M. (2018) Effect on kinematic gait variables of two methods of inertial measurement unit sensor attachment to the extremities of horses under controlled conditions of treadmill exercise in sound horses at the walk and trot: A pilot study. Pferdeheilkunde 34, 333-340; DOI 10.21836/PEM20180403

Correspondence: Dr. Antonio Cruz, Dpto. de Medicina y Cirugía Animal, Facultad de Veterinaria, Universidad Cardenal Herrera-CEU, CEU Universities C/ Tirant lo Blanc 7. 46115 Alfara del Patriarca Valencia, Españia; antonio.cruzmadorran@uchceu.es

\section{Introduction}

Recently, much effort has been made to develop portable kinematic gait analysis technology for use in equine practice. With the advent of miniaturised inertial measurement units (IMUs), it is possible to evaluate horses performing under 'real-life' conditions, outside of the laboratory (Pfau 2011). IMUs have the capability of measuring acceleration and angular rate in a three-dimensional space. In humans, Cuesta-Vargas et al. (2010) performed a systematic comparison of IMUs with other tools for measuring human movement, and concluded that IMUs offer a reliable method to assess human gait. IMU systems are commercially available to the equine clinician. The currently available systems focus on detecting asymmetric movement with higher precision than the human eye, but they do not define other movement patterns such as joint angles and displacements in the sagittal and coronal planes (Keegan 2007). The simultaneous spatial and temporal assessment of the four limbs is important in our opinion to the understanding of the entire gait.

Joint range of motion, acceleration, and range of displacement of extremities in orthogonal (sagittal and coronal) planes can be measured by IMUs by instrumenting the extremities directly (See/ et al. 2014). These parameters, when integrated with time, provide the evaluator with spatio-temporal information regarding the leg's movement and thus to assess the gait not only by meanings of symmetry.
The system reported in the present study requires the placement of IMU sensors on the distal antebrachium and crus by means of a strap, in addition to all the metacarpi/tarsi by brushing boots. The straps consist of a rubber band, elastic bandage and velcro ${ }^{\circledR}$ (Velcro companies, Manchester, UK). While horses are used to wear brushing boots, the presence of elastic straps at the required locations are unknown to them. These straps applied by pressure may affect the kinematics of the leg as they introduce a sensory element unknown to the horse. Sensory stimuli have been shown to affect horse's movement before (Clayton et al. 2011). We observed an abnormal response characterized by hyperflexion of the tarsi in most horses following placement of the straps. However while this visible effect seem to disappear quickly, there is no data as to what effects the presence of straps secured to the distal tibia or antebrachium may have during locomotion. Therefore, the objective of this study was to investigate the effects of straps by comparing them to a glued-on method of attaching the sensor to the required location on the extremity.

\section{Materials and Methods}

Horses

Three Franches-Montagnes stallions, ranging from 11 to 16 years of age, were used in this study. All of the horses were 

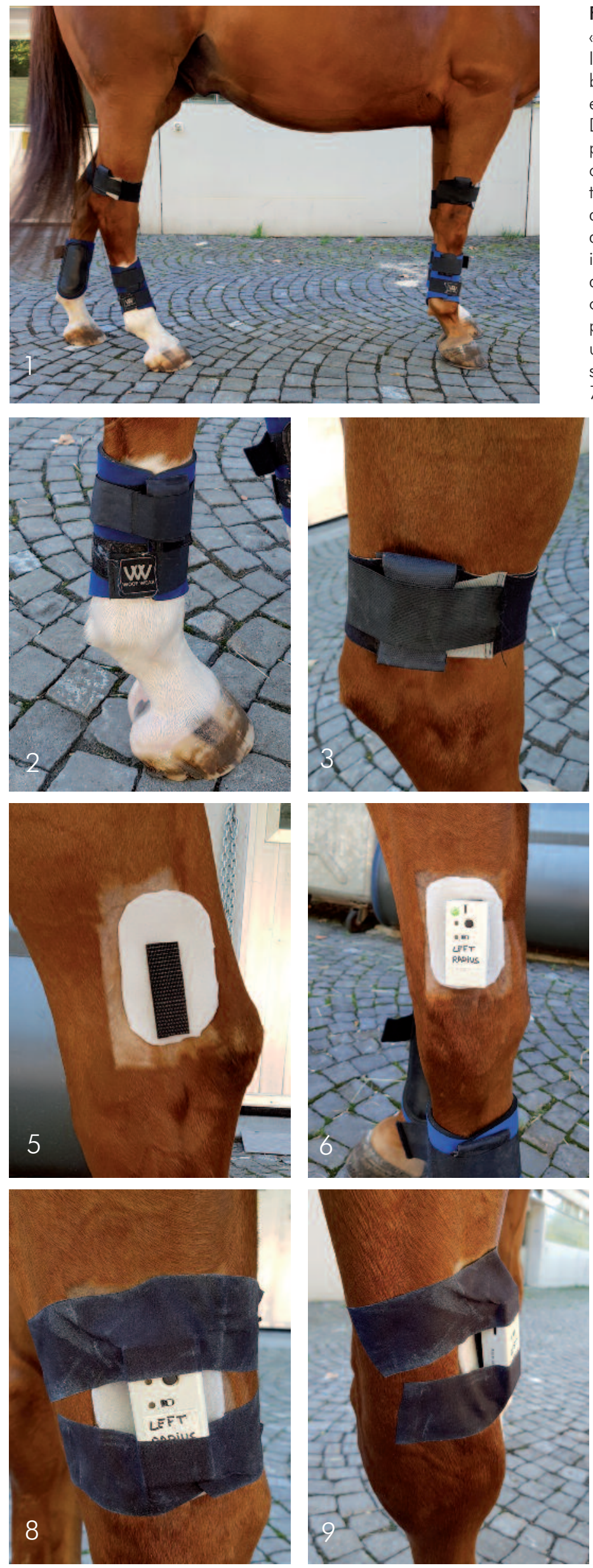

Fig. 1 One of the 3 horses completely instrumented and ready for a «straps-on» trial. Using an extremity-mounted IMU-system. The eight IMU-sensors are placed in the custom-fitted pouches on the brushing boots at the distal aspect of the metacarpi/metatarsi, as well as on the elastic straps around the distal aspect of the radii and tibias. Fig. 2 Detail of the brushing boot (Woof Ware) with its custom-fitted little pouch to safely accommodate the sensor. Fig. 3 Detail of the custom-made elastic strap (GaitSmart ${ }^{\text {TM }}$ Peagasus) with its custom-fitted little pouch to safely accommodate the sensor. Placed on the distal aspect of the tibia. The same kind of straps were used on the front leg around the distal part of the radius (see figure 1). Fig. 4 Front limb in preparation for the "glued-on" trials. An area of $12 \times 8 \mathrm{~cm}$ on the distolateral aspect of the radius, $10 \mathrm{~cm}$ proximal to the styloid process of the ulna was clipped with a \#40 blade and cleaned with $70 \%$ isopropyl alcohol. Then glue spray (Skin Adhesive Spray for Animals) was used in the clipped area, prior to gluing a piece of self-adhesive dressing (Animal Polster) of $10 \times 6 \mathrm{~cm}$. Over this dressing, a piece of $7 \times 2 \mathrm{~cm}$ of $3 \mathrm{M}^{\mathrm{TM}}$ dual lock ${ }^{\mathrm{TM}}$ tape was adhered to the Polster ${ }^{\mathrm{TM}}$.

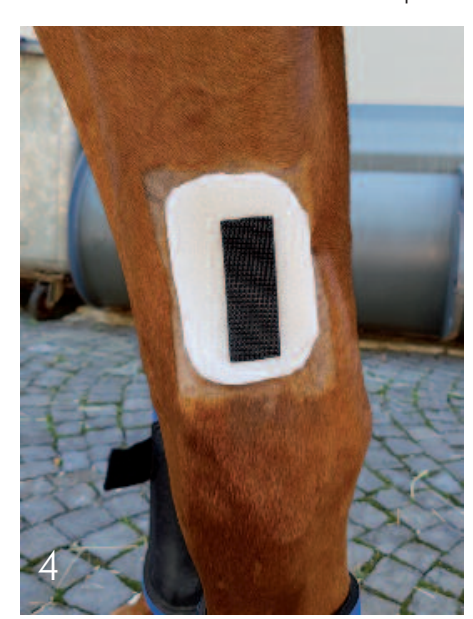

Fig. 5 Hind limb in prepara-

tion for the "glued-on" trials. This included an area on the distolateral aspect of the tibia, just dorsal to the groove of the Achilles tendon about $10 \mathrm{~cm}$ proximal to the lateral maleollus of the fibula. An area of $12 \times 8 \mathrm{~cm}$ was clipped with a \#40 blade and cleaned with $70 \%$ isopropyl alcohol. Then glue spray (Skin Adhesive Spray for Animals) was used in the clipped area, prior to gluing a piece of self-adhesive dressing (Animal Polster) of $10 \times 6 \mathrm{~cm}$. Over this dres-

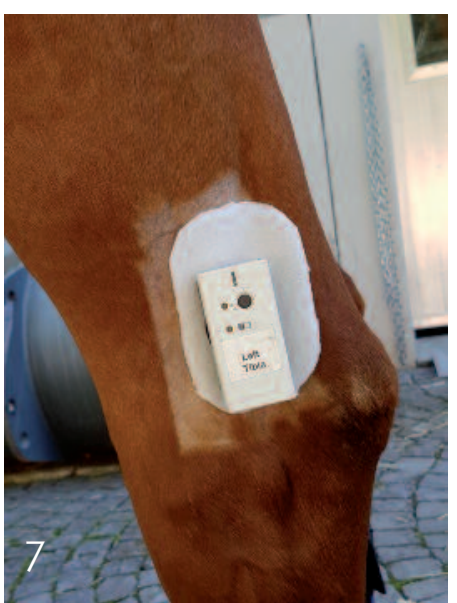

sing, a piece of $7 \times 2 \mathrm{~cm}$ of $3 M^{T M}$ dual lock ${ }^{T M}$ tape was adhered to the Polster ${ }^{\mathrm{TM}}$. Fig 6 After the preparation seen and described on figure 4 with the corresponding sensor on. The piece of tape on the radius matched the length size of the sensors, which were also equipped with a corresponding piece of $3 \mathrm{M}^{T M}$ dual lock ${ }^{T M}$ tape on their backside. Fig. 7 After the preparation seen and described on figure 5 with the corresponding sensor on. The piece of tape on the tibia 47. matched the length size of Q.1 the sensors, which were also equipped with a corresponding piece of $3 \mathrm{M}^{\text {TM }}$ dual lock $^{\text {TM }}$ tape on their backside. Fig. 8 Sensor attachment method for the "gluedon" trials at the radius readyto-use. Seen from the side. Fig. 9 Sensor attachment method for the "glued-on" trials at the radius ready-touse. Seen from cranial. Fig. 10 Sensor attachment method for the "glued-on" trials at the radius ready-touse. Seen from caudal. 
owned by the Haras National Stud Center in Avenches, Switzerland. Horses were sound, on regular work 5 times per week and excluded when visually lame, unhealthy or under any medical treatment, checked by Dr. Antonio Cruz and Dr. Ugo Maninchedda. The selected horses were in good physical condition and conformation and accustomed to working on a treadmill (Kagra, Graber AG, Fahrwagen, Switzerland) prior to the beginning of the study as per previously published information (Buchner et al. 1994).

\section{Inertial measurement sensor system}

Data collection was carried out using a commercially available IMU system (GaitSmartTM Pegasus, European Technology for Business Ltd., ETB, Hertfortshire, UK). The IMUs record six degrees of freedom (6 DOF), outputs of acceleration and angular rotation along three orthogonal axes. Four IMUs were mounted into brushing boots on the distolateral aspect of the metacarpi/metatarsi (Figure 1 and Figure 2). The other 4 IMUs were either mounted onto the distal tibias and distal radii by means of customized straps (Figure 3) or directly glued on the skin (Figure 6). As described in the patent each IMU (total mass $54 \mathrm{~g}$ and size $73 \times 36 \times 19 \mathrm{~mm}$ ) contained a triaxial $5 \mathrm{~g}$ accelerometer and three single-axis $1200 \mathrm{deg} / \mathrm{s}$ gyroscopes followed by anti-aliasing hardware filters with a cut-off frequency of approximately $50 \mathrm{~Hz}$. Sampling was done with a 12-bit analogue-to-digital converter at a frequency of $102.4 \mathrm{~Hz}$. Each IMU was factory set within $1 \mathrm{ppm}(3.6 \mathrm{~ms}$ per hour) of a reference time, achieving less than $10 \mathrm{~ms}$ per hour relative drift between units after synchronization. The IMUs were time stamped and synchronized immediately before the start of each horse's trials by a simultaneous pulse sent to the respective units, using specifically written software (Poseidon $9^{\text {TM }}$, ETB, Hertfordshire, UK). This software was also used for the recording and automated processing of the data. The sensors contained a precision clock and a memory storage service card (Cruz et al. 2017).

\section{Glued-on method description}

The current method was obtaining through a refining process that involved several trials. Previously to this study another three horses were instrumented with the IMUs. Although the sensors didn't detach during treadmill exercise, they appeared to visually wobble significantly which led to unstable sensor signals. In a second trial, cyanoacrylate glve (LOCTITE, Henkel, Düsseldorf, Germany) was added and once the sensors were placed two stripes of tesa ${ }^{\circledR} 53949$ PV2 tape (Tesa SE, Norderstedt, Germany) (14 cm long) were horizontally placed over the upper and lower third of the sensor. This method did not improve the quality of the signals from the sensors.

Finally, the current method was employed. The skin areas to affix the sensors by means of glue were prepared. This included an area on the distolateral aspect of the tibia, just dorsal to the groove of the Achilles tendon about $10 \mathrm{~cm}$ proximal to the lateral maleollus of the fibula and on the distolateral aspect of the radius, $10 \mathrm{~cm}$ proximal to the styloid process of the ulna, placements equivalent to the straps. Briefly an area of $12 \times 8 \mathrm{~cm}$ was clipped with a \#40 blade and cleaned with $70 \%$ isopropyl alcohol. Then glue spray (Skin Adhesive Spray for Animals, 900-2697, $150 \mathrm{ml}$, Henry Schein UK Holdings Ltd., Gillingham, UK) was used in the clipped area, prior to gluing a piece of self-adhesive dressing (Animal Polster, 012116 , Snögg by Norgeplaster AS, Kristiansand, Norway) of $10 \times 6 \mathrm{~cm}$. Over this dressing, a piece of $7 \times 2 \mathrm{~cm}$ of $3 \mathrm{M}^{\mathrm{TM}}$ dual lock ${ }^{\text {TM }}$ tape was adhered to the Polster ${ }^{\text {TM }}$ (Figure 4 and Figure 5). This piece of tape matched the length size of the sensors, which were also equipped with a corresponding piece of $3 M^{\mathrm{TM}}$ dual lock ${ }^{\mathrm{TM}}$ tape on their backside. The $3 \mathrm{M}^{\mathrm{TM}}$ dual lock $^{\mathrm{TM}}$ tape was placed at the same position where the sensors were mounted when placed in the straps (Figure 6 and Figure 7). Two $14 \mathrm{~cm}$ long stripes of tape (Tesa ${ }^{\circledR} 53949$ PV2) were placed on the upper and lower third of each sensor to provide additional stability and prevent them from wobbling and making sure that they did not wrap $360^{\circ}$ around the leg (Figure 8, Figure 9 and Figure 10). Following the placement of straps or glued dual lock tape in the distal radius and tibia, the brushing boots were mounted in the metacarpal or metatarsal regions. The brushing boots were equipped with a custom fitted pouch to safely accommodate the sensors on the distolateral aspect of the metacarpi and metatarsi (Figure 2). Prior to placing and turning the sensors on, the horses were exercised on the treadmill at a walk for 10 minutes and at trot for 5 minutes to reach steady state locomotion (Buchner et al. 1994) and for the horses to accustom to the presence of the straps. Immediately after mounting the straps the horses tended to show hyperflexion of their tarsi. The gait appeared visually normal within 2 minutes. The sensors were then synchronized, placed on and aligned to the longitudinal axis of the bone segment by eye.

\section{Data}

The sensors are programmed to determine the cycle associated with each stride via a proprietary algorithm (Whalley and Hodgins 2014). The spatiotemporal variables reported by the system define some aspects of the kinematic characteristics of the gait and include:

\section{Temporal}

The system is able to measure limb phasing variables, stride duration (in seconds), percentage timing within a stride for maximal protraction and retraction of third metacarpal and metatarsal bones (as expressed by percentage of the stride) and diagonal asymmetry by taking the left hind as reference limb (Cruz et al. 2017).

\section{Spatial}

the range of motion (ROM) in degrees referring to the sagittal angles of the tarsal/carpal joint and segment angles of metacarpi/tarsi and tibias/radii, the transversal ROM of metacar$\mathrm{pi} /$ tarsi, the radii and the tibias in degrees, the symmetry (\%) of each segment and joint ROM was calculated as the difference of left minus right divided by the mean of both measurements. With the exception of the tarsus and carpus, the rest of the angles, which defined the ROM in this study were segment angles. A segment angle is the resulting angle that the segment subtends from its maximum retracted position to its maximum protracted position. The tarsus and the carpus angles are joint angles which is the angle subtended between 
two segments which rotate about the joint. For the transversal angle, it is the maximum range the segment moves through the stride in the frontal plane (Cruz et al. 2017).

The stride frequency $\left(\mathrm{s}^{-1}\right)$ as well as the stride length $(\mathrm{m})$ could be calculated. Trotting and walking speeds were predetermined.

\section{Data collection protocol for each horse}

All trials were taken at the same speed, for walk it was $1.88 \mathrm{~m} / \mathrm{s}$ and at trot it was $3.33 \mathrm{~m} / \mathrm{s}$. The speed was taken directly from the treadmill's calibrated speedometer.

Prior to the beginning of the first recording, the horses were warmed-up by walking them in a horse walker for 20 minutes. Then they were walked for 10 minutes and trotted for 5 minutes on the treadmill to reach steady state locomotion (Buchner et al 1994). Following placement of the sensors the horse had to remain still for 10 seconds, for the sensors to find a stationary period to self-calibrate. This calibration enables the system to define the gravitational vector. In total 8 IMUs were used on all of the horses. All horses were halter handled by the same person with a loose hanging rope without interfering with the horse's movement. External factors, such as noise or moving objects, were eliminated as far as possible. If a horse's level of distraction or excitement was significantly noticeable, the measurement was discarded and repeated directly, once the conditions were optimal.

Per measurement the horses were walked for a minimum of 30 strides, then trotted for a minimum of 30 strides and then stopped for a few seconds. Three consecutive measurements were taken. Strides were counted visually and data was collected in triplicate (three measurements coded for analysis as measurements 1, 2 and 3). At the end of each horse's data collection period, the sensors were switched off and removed from their locations. Then, they were connected to the laptop where the data was downloaded for future analysis. In the end a total of 18 measurements sets per horse were performed on the three horses, including nine with straps on and nine with glued-on sensors at the walk and trot. Ending up with 36 recordings per horse. All measurements were included in the analysis.

\section{Data analysis by software}

The system included a software (Poseidon $9^{\text {TM }}$, ETB, Hertfordshire, UK), eight IMU sensors, four brushing boots, four straps and a delivered laptop. The data collected by the sensors was downloaded onto this specific laptop and analysed by the software. From the display of temporal and orientation outputs the authors manually and visually selected a window of data with steady locomotion including at least 8-10 strides to perform the analysis and avoiding the beginning and the end of the analysed gait segment. For the purpose of this study steady locomotion was characterized by a regular signal from each sensor, as well as regular stride duration, as can be seen in the user's interface of the system. The system calculates the orientation and temporal events of each segment, then calculates the joint angles as a relationship of two adjacent segments and the limb phasing as the relative timing of segments between each other.

\section{Statistical analysis}

The descriptive data analysis was done using commercial software NCSS10 (NCSS Statistical Software, Kaysville, Utah, United States). Data were examined for the presence of outliers and tested for normality. Values below or above the 2.5 th and 97.5th percentiles were considered to be outliers and their origin investigated. A repeated measures analysis of

Table 1 - Shortened list of temporal and spatial gait variables (mean (SD)) measured by use of extremity-mounted IMUs during trotting of 3 sound horses under controlled treadmill exercise. P-values calculated by performing a repeated measures ANOVA with horses as subjects and straps or "glued-on" as within factor.

\begin{tabular}{|c|c|c|c|}
\hline TROT & Mean Glued-on (mean SD & Mean Straps (mean SD) & P-value (Straps) \\
\hline Stride duration (s) & $0.73(0.02)$ & $0.73(0.02)$ & 0.540732 \\
\hline Stride lenght (m) & $2.42(0.01)$ & $2.41(0.08)$ & 0.540732 \\
\hline Stride frequency $\left(\mathrm{No}^{\circ}\right.$ Strides $\times \mathrm{min}^{-1}$ ) & $81.97(2.74)$ & $82.10(2.62)$ & 0.567876 \\
\hline \multicolumn{4}{|l|}{ Sagittal ROM } \\
\hline Carpus left $\left(^{\circ}\right)$ & $83.03(6.92)$ & $73.13(2.22)$ & 0.000000 \\
\hline Carpus right $\left({ }^{\circ}\right)$ & $86.84(7.48)$ & $74.92(6.31)$ & 0.000000 \\
\hline Radius left $\left(^{\circ}\right)$ & $70.50(2.69)$ & $61.57(3.03)$ & 0.000000 \\
\hline Radius right $\left({ }^{\circ}\right)$ & $72.29(4.41)$ & $61.23(3.86)$ & 0.000000 \\
\hline Tarsus left $\left(^{\circ}\right)$ & $44.51(6.78)$ & $38.20(4.42)$ & 0.000000 \\
\hline Tarsus right $\left(^{\circ}\right)$ & $46.28(7.70)$ & $40.96(5.36)$ & 0.000000 \\
\hline Tibia left $\left(^{\circ}\right)$ & $47.60(6.52)$ & $44.76(7.41)$ & 0.000137 \\
\hline Tibia right $\left({ }^{\circ}\right)$ & $49.25(6.85)$ & $48.43(3.88)$ & 0.31704 \\
\hline Metacarpus left $\left(^{\circ}\right)$ & $85.62(4.26)$ & $85.51(4.35)$ & 0.771019 \\
\hline Metacarpus right $\left({ }^{\circ}\right)$ & $85.73(3.18)$ & $84.93(3.55)$ & 0.092235 \\
\hline Metatarsus left $\left({ }^{\circ}\right)$ & $55.92(2.45)$ & $55.83(2.72)$ & 0.871604 \\
\hline Metatarsus right $\left({ }^{\circ}\right)$ & $55.26(2.22)$ & $54.57(3.13)$ & 0.19861 \\
\hline
\end{tabular}


Table 2 - Shortened list of temporal and spatial gait variables (mean (SD)) measured by use of extremity-mounted IMUs during walking of 3 sound horses under controlled treadmill exercise. P-values calculated by performing a repeated measures ANOVA with horses as subjects and straps or "glued-on" as within factor.

\begin{tabular}{|c|c|c|c|}
\hline WALK & Mean lued-on (mean SD) & Mean Straps (mean SD) & P-value (Straps) \\
\hline Stride duration (s) & $1.08(0.06)$ & $1.07(0.07)$ & 0.16428 \\
\hline Stride lenght (m) & $2.03(0.11)$ & $2.01(0.13)$ & 0.16428 \\
\hline Stride frequency $\left(\mathrm{No}^{\circ}\right.$ Strides $\times \mathrm{min}^{-1}$ ) & $55.72(3.12)$ & $56.31(3.71)$ & 0.131641 \\
\hline \multicolumn{4}{|l|}{ Sagittal ROM } \\
\hline Carpus left $\left(^{\circ}\right)$ & $67.22(7.14)$ & $60.21(4.57)$ & 0.000000 \\
\hline Carpus right $\left(^{\circ}\right)$ & $70.71(6.47)$ & $60.61(6.84)$ & 0.000000 \\
\hline Radius left $\left(^{\circ}\right)$ & $75.45(3.87)$ & $65.09(4.55)$ & 0.000000 \\
\hline Radius right $\left({ }^{\circ}\right)$ & $77.36(6.78)$ & $67.32(4.60)$ & 0.000000 \\
\hline Tarsus left $\left(^{\circ}\right)$ & $37.75(3.17)$ & $33.13(1.81)$ & 0.000000 \\
\hline Tarsus right $\left({ }^{\circ}\right)$ & 37.80 (4.79) & $35.35(3.44)$ & 0.004906 \\
\hline Tibia left $\left(^{\circ}\right)$ & $56.47(2.97)$ & $53.78(2.92)$ & 0.000301 \\
\hline Tibia right $\left({ }^{\circ}\right)$ & 57.60 (3.93) & $56.80(1.87)$ & 0.275598 \\
\hline Metacarpus left $\left(^{\circ}\right)$ & $76.04(1.90)$ & $76.01(1.70)$ & 0.931732 \\
\hline Metacarpus right $\left({ }^{\circ}\right)$ & $75.74(1.37)$ & $75.20(1.44)$ & 0.11881 \\
\hline Metatarsus left $\left(^{\circ}\right)$ & $61.90(3.68)$ & $62.04(3.12)$ & 0.781793 \\
\hline Metatarsus right $\left({ }^{\circ}\right)$ & $61.76(2.97)$ & $61.78(2.86)$ & 0.976879 \\
\hline \multicolumn{4}{|c|}{ 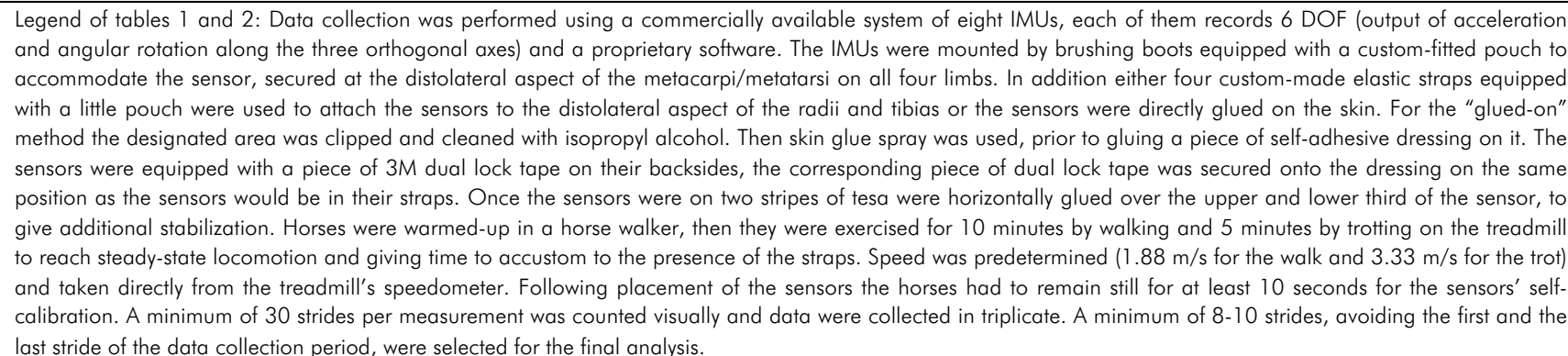 } \\
\hline
\end{tabular}

variance with horses as subject ( $n=$ three) and a categorical variable ("straps" or "glued-on") as within factor, was performed and a post-hoc Bonferroni multi-comparison test if a significant effect $(P<0.05)$ was found.

\section{Results \\ Trot (table 1)}

A repeated measures ANOVA, showed significant differences mainly on the sagittal range of motion of tarsi, carpi and radii on both sides and on the left tibia $(P<0.001)$. The horses showed on average $3.82 \pm 3.00$ degrees less range of motion on tarsi and tibia and $10.46 \pm 1.52$ degrees less range of motion on carpi and radii with straps on than with the glued-on method at the trot.

\section{Walk (table 2)}

The main significant differences for the walk were found in the sagittal ROM of tarsus, carpus and radius on both sides $(P<0.01)$ and on the left tibia $(P<0.001)$. The horses showed on average $2.64 \pm 1.98$ degrees less ROM on tarsi and tibia and $9.38 \pm 2.37$ degrees less $R O M$ on carpi and radii with straps on than with the glued-on method at the walk.

\begin{tabular}{lcc}
\hline \multicolumn{3}{l}{$\begin{array}{l}\text { Table } 3 \text { - Mean loss on sagittal ROM using the straps as } \\
\text { attachment method. Loss of ROM straps vs. glued-on (mean SD) }\end{array}$} \\
\hline \multicolumn{1}{c}{ Location } & $5.81(0.50)$ & Walk \\
\hline Tarsus $\left(^{\circ}\right)$ & $1.83(1.01)$ & $1.75(1.09)$ \\
Tibia $\left(^{\circ}\right)$ & $3.82(3.00)$ & $2.64(1.98)$ \\
Hind leg $\left(^{\circ}\right)$ & $10.91(1.01)$ & $8.56(1.55)$ \\
Carpus $\left(^{\circ}\right)$ & $10.00(1.07)$ & $10.20(0.16)$ \\
Radius $\left(^{\circ}\right)$ & $10.46(1.52)$ & $9.38(2.37)$ \\
Front leg $\left(^{\circ}\right)$ & \multicolumn{3}{c}{$-9.92^{\circ}$} \\
\hline Mean loss ROM straps vs. glued-on & $-3.23^{\circ}$ \\
Front Legs & $-7,14^{\circ}$ \\
Hind legs & $-6.01^{\circ}$ \\
Trot & \\
Walk &
\end{tabular}

\section{Discussion}

This pilot study investigated the effect on gait variables of two different sensor attachment methods of an IMU system. The study suggests that the straps used to attach the IMU to the distal tibia and radius seem to have an influence on some of the gait variables investigated such as the ROM of the corre- 
sponding joints and bone segments, specifically the carpi, tarsi, radii and tibias. The placement of straps is associated with a reduced sagittal ROM at walk and trot, suggesting that the straps may impede the horse from moving the extremities completely freely. As the results show, there's only a reduced sagittal ROM on the radii/tibias and not on the metacarpi/metatarsi. Therefore, we can conclude that the reduction in the sagittal ROM of the carpi/tarsi is mainly caused by a reduced motion on the proximal segments (radii and tibias) where the straps are located, according to the dependency of the joint angle to the motion of its proximal and distal segments. This difference could be as high as a reduction of 12 degrees on the sagittal ROM when the straps were used as attachment method. The mean changes on the values at the walk were similar although slightly smaller than those seen at the trot. On average, there is a decrease of 6.01 degrees at the walk and 7.14 degrees at the trot. The impact of the presence of the straps on the front limbs (reduction of $10.46^{\circ} \pm 1.52^{\circ}$ at the trot and $9.38^{\circ} \pm 2.37^{\circ}$ at the walk) seems to be larger than on the hind limbs (reduction of $3.82^{\circ} \pm 3.00^{\circ}$ at the trot and $2.64^{\circ} \pm 1.98^{\circ}$ at the walk) (table 3). Horses didn't seem to get used to the presence of the straps as this effect was reproduced regardless of repetition number. The first observation immediately after the straps are placed on, is that the horses show a hyperflexed gait on the hind limbs, in a similar way many horses react after mounting travelling boots. It could be that the horse first tries to eliminate the foreign sensation of the straps, but visually within two minutes it appears to adapt to their presence after habituation or acceptance to their presence and pressure. This study therefore showed and suggests that while visually, the presence of straps initially increases flexion of the tarsi, the effect seems to be reversed during motion after habituation.

The effects seen in this study may be due to a mechanical restriction produced by the straps as when the horses flex the tarsi and the carpi the muscles and tendons under the straps, namely the deep and the superficial digital flexor tendons shorten and thicken (Butcher et al. 2009), potentially producing a sensory stimulus altering the sagittal ROM. Range of motion changes in response to sensory alterations have been reported in the horse before (Clayton et al. 2011 ). In another study reduced ROM in swing phase on the fetlock joint was found and suggested of being an effect of elevated proprioception due to athletic taping of the fetlock (Ramon et al. 2004). The elevated proprioception and therefore reduced ROM due to athletic taping was first described by $A l t$ et al. (1999) on human ankle kinematics.

Repeatability of measurements with this IMU system under conditions of treadmill exercise has been reported before (Cruz et al. 2017).

We tried to standardise the methodology to place the straps by training and designating the same people to place the straps. However it is possible that variation existed as to how much tension was placed on the elastic straps at different times. This constitutes a limitation of the present study and the use of a dynamometer or strain gauge to specifically determine how much tension was placed on the straps as an element of variability (Crawford et al. 1990) although not simple, could be implemented. Forner-Cordero et al. (2008) evaluated the preload force of the attachment by bandages qualitatively on man. High preload force (hard) was obtained by strapping the bandage until the maximum level the subject could sustain without discomfort. Low preload (soft) force was obtained by leaving the bandage loosely wrapped. They described in their results that the level of preloading force provided by the bandage affected the measurements significantly, as it modified the stiffness. With soft preloading force, the natural frequency was too low, increasing measuring errors. The natural frequency of the attachment increases with higher loading force.

It is possible that our results, given our small sample size and lack of precise standardization of the tension placed on the straps, are inaccurate. Therefore a larger study correcting such limitation may help us to further determine the validity of our results.

However, the lack of measurement, repetition or subject effect as well as the repeatability obtained suggests that our findings may apply to the broad equine population.

When using this system for the assessment of gait quality or to compare with optical kinematic systems we recommend to take into account specifically a possible underestimation of sagittal tarsi and carpi ROM. Additionally implementing a different attachment method that does not include a strap, or perhaps a different type of strap that would not interfere with movement could be developed.

\section{Abbreviations}

$\begin{array}{ll}\text { DOF } & \text { degrees of freedom } \\ \text { IMU } & \text { inertial measurement unit } \\ \text { LF } & \text { left front limb } \\ \text { LH } & \text { left hind limb } \\ \text { RF } & \text { right front limb } \\ \text { RH } & \text { right hind limb } \\ \text { ROM } & \text { range of motion }\end{array}$

\section{Manufacturer's addresses}

- Animal Polster, 012116 , Snögg Norgeplaster AS, Kristiansand, Norway

- GaitSmart ${ }^{T M}$ Pegasus, European Technology for Business Ltd., ETB, Hertfortshire, UK

- Kagra, Graber AG, Fahrwagen, Switzerland

- LOCTITE, Henkel, Düsseldorf, Germany

- NCSS10, NCSS Statistical Software, Kaysville, Utah, United States

- Poseidon $9^{\text {TM }}$, ETB, Hertfordshire, UK

- Skin Adhesive Spray for Animals, 900-2697, 150 ml, Henry Schein UK Holdings Ltd., Gillingham, UK

- tesaband ${ }^{\circledR} 53949$ PV2, tesa SE, Norderstedt, Germany

- 3MTM Dual Lock ${ }^{T M}$ Reclosable Fastener, 3M, St. Paul, MN, United States

- Woof Ware, Bodmin, Cornwall, UK

- velcro ${ }^{\circledR}$, Velcro companies, Manchester, UK

\section{Acknowledgments}

The authors would like to thank the Swiss National Haras Stud Center in Avenches for providing us with the horses and let us using their infrastructure and the European Technology for Business for the loan of the equipment used in this pilot study. 
The authors would like to acknowledge European Technology for Business for the loan of the equipment utilized in this study. The Swiss Stud Farm provided the horses for the study.

\section{Ethical Considerations}

This study was approved by the Swiss Cantonal Authority on Animal Care following Institutional Animal Care Guidelines.

\section{Sources of funding}

Study supported by the Institute Suisse de médicine équine.

\section{Conflict of interest statement}

There's no conflict of interests, which had to be considered.

\section{References}

Alt W., Lohrer H., Gollhofer A. (1999) Functional properties of adhesive ankle taping: neuromuscular and biomechanical effects before and after exercise. Foot Ankle Int. 20, 238-245; DOI 10.1177/ 107110079902000406

Buchner H. H. F., Savelberg H. H. C. M., Schamhardt H. C., Merkens H. W., Barneveld A. (1994) Habituation of horses to treadmill locomotion. Equine Vet. J. 26, 13-15; DOI 10.1111/j.20423306.1994.tb04865.x

Butcher M. T., Hermanson J. W., Ducharme N. G., Mitchell L. M., Soderholm L. V., Bertram J. E. A. (2009) Contractile behavior of the forelimb digital flexors during steady-state locomotion in horses (Equus caballus): An initial test of muscle architectural hypotheses about in vivo function. Comp. Biochem. Physiol. A, 152, 100-114; DOI 10.1016/j.cbpa.2008. 09.007
Clayton H. M., Lavagnino M., Kaiser L. J., Stubbs N. C. (2011) Evaluation of biomechanical effects of four stimulation devices placed on the hind feet of trotting horses. Am. J. Vet. Res. 72, 14891495; DOI 10.2460/ajvr.72.11.1489

Crawford W. H., Vanderby J. R. R., Neirby D., Nordheim E.V., Libbey C. J. (1990) The energy absorption capacity of equine support bandages. Part I: Comparison between bandages placed in various configurations and tensions. Vet. Comp. Orthop. Traumatol. 1, 2-9

Cruz A. M., Maninchedda U. E., Burger D., Wanda S., Vidondo B. (2017) Repeatability of gait pattern variables, measured by use of extremity-mounted inertial measurement units in nonlame horses during trotting. Am. J. Vet. Res. 78, 9; DOI: https://doi.org/ 10.2460/ajvr.78.9.1011

Cuesta-Vargas A., Galan-Mercant A., Williams J. M. (2010) The use of inertial sensors system for human motion analysis. Physical Therapy Reviews 15, 6, 462-473; DOI: http://dx.doi.org/10.1179/ $1743288 \times 11$ Y.0000000006

Forner-Cordero A., Mateu-Arce M., Forner-Cordero I., Alcántara E., Moreno J. C., Pons J. L. (2008) Study of the motion artefacts of skin-mounted inertial sensors under different attachment conditions. Inst. Phys. Engineer. Med. 29, 4; DOI: 10.1088/09673334/29/4/N01

Keegan K. G. (2007) Evidence-Based Lameness Detection and Quantification. Veterinary Clinics of North America: Equine Practice 23, 2, 403-423; DOI: https://doi.org/10.1016/i.cveq. 2007.04.008

Pfau T. (201 1) Practical Assessment of Movement Symmetry in Horses: Use of inertial sensors during clinical lameness exams. London Royal Veterinary College.

Ramon T., Prades M., Armengou L., Lanovaz J. L., Mullineaux D. R., Clayton H. M. (2004) Effects of athletic taping of the fetlock on distal limb mechanics. Equine Vet. J. 36, 8, 764-768; DOI: $10.2746 / 0425164044848127$

Seel T., Raisch J., Schaver T. (2014) IMU-Based joint angle measurement for gait analysis. Sensors, 14, 4, 6891-6909; DOI: 10.3390/s 140406891

Whalley A., Hodgins D. (2014) Assessment of gait. Patent Number 8.715.208 B2, May 6, 2014, United States of America 


\section{Effekt zweier Methoden der kinematischen Ganguntersuchung mittels an den Extremitätren von Pferden befestigten Trägheitssenosorenunter kontrollierten Bedingungen in Schritt und Trab auf dem Laufband - Eine Pilotstudie}

In jüngtser Vergangenheit wurden große Anstrengungen unternommen, für die Pferdepraxis tragbare kinematische Technologien zur Ganganalyse zu entwickeln. Die Studie diente der Untersuchung zweier verschiedener Befestigungsmethoden für Trägheitssensoren am distalen Radius und Tibia beim Pferd. Die Untersuchung sollte allfällige Auswirkungen auf die kinetischen Parameter der für die Pferde unbekannten elastischen Bandagen aufzeigen. Es wurde eine Cross-over-Studie durchgeführt, wobei bei allen Pferden beide Methoden, die Sensoren zu befestigen, getestet wurden: mittels elastischen Bandagen einerseits und geklebt andererseits. Insgesamt 8 Trägheitssensoren bildeten das Messsystem für ein Pferd. Diese wurden distolateral der Metacarpi und Metatarsi, sowie distolateral an Radius und Tibia angebracht. Die Datenerfassung erfolgte zu drei verschiedenen Zeiten während der Bewegung im Schritt und Trab auf dem Laufband. Eine extra designte Software verarbeitete die Signale der Beschleunigungssensoren und Gyroskope. Dadurch wurden zeitliche und räumliche Daten, welche die vom System zuvor festgelegten kinetischen Variablen darstellten, ausgelesen. Repeated-measures ANOVAs wurden angefertigt um Differenzen zwischen Gruppen aufzuzeigen. Drei zufällig gewählte Freiberger Hengste, im Alter von 11 bis 16 Jahren, nahmen an der Studie teil. Besitzer der Pferde war das schweizerische Nationalgestüt in Avenches. Alle Pferde waren gesund, in guter physischer Kondition und an die Arbeit auf dem Laufband gewohnt. Bei sichtbarer Lahmheit oder falls die Pferde unter medizinischer Versorgung standen, wurden sie von der Studie ausgeschlossen. Die Datenaquirierung wurde mit einem kommerziell erhältlichen IMU-System GaitSmart ${ }^{\mathrm{TM}}$ Pegasus durchgeführt. Die Trägheitssensoren zeichnen in 6 Freiheitsgraden auf, die Ergebnisse der Beschleunigung und Winkelrotationen werden im dreidimensionalen Raum berechnet. Vier der Trägheitssensoren werden in kleinen Taschen befestigt an Gamaschen distolateral an Metatarsi und Metacarpi angebracht. Die anderen vier Sensoren wurden entweder distolateral an Tibia und Radius mittels vom Hersteller entworfenen elastischen Bandagen angebracht oder direkt auf die Haut geklebt. Eine Fläche von $8 \times 12 \mathrm{~cm}$ distolateral an der Tibia, gerade dorsal der Einziehung des Fersensehnenstrangs, ca. $10 \mathrm{~cm}$ proximal des lateralen Malleolus der Fibula und distolateral am Radius, $10 \mathrm{~cm}$ proximal des Proccessus styloideus der Ulna, gleich dem Ort der Befestigung in den Bandagen, wurde geschoren und mit 70\% Isopropylalkohol gereinigt. Ein Klebespray an dieser Stelle bildete die Basis für das Aufkleben eines $10 \times 6 \mathrm{~cm}$ grossen, selbstklebenden Polsters. Auf dieses Polster wurde ein Stück $3 M^{\text {TM }}$ dual lock ${ }^{T M}$ Tape $(2 \times 7 \mathrm{~cm})$ aufgeklebt. Die Trägheitssensoren wurden auf ihrer Rückseite mit dem passenden Stück 3M ${ }^{\text {TM }}$ dual lock ${ }^{\text {TM }}$ Tape ausgestattet. Zwei ca. $14 \mathrm{~cm}$ lange Gewebebandstreifen wurden horizontal über dem oberen und unteren Drittel jedes Sensors geklebt um zusätzliche Stabilität und Schutz vor Wacklern zu gewährleisten. Die Daten von jedem Pferd wurden inklusive Informationen zu Alter, Rasse und Geschlecht aufgezeichnet und gespeichert. Für alle Messungen galten die gleichen Geschwindigkeiten: 1,88 m/s im Schritt und 3,33 m/s im Trab, gemessen durch einen in das Laufband integrierten Geschwindigkeitsmesser. Externe Faktoren wie Lärm oder sich bewegende Objekte, wurden soweit möglich eliminiert. Pro Messung wurden die Pferde für mindestens 30 Schritte bewegt. Die Daten wurden in Tripletts gesammelt, welche jeweils 3 Mal repetiert wurden. Dies ergab 3 Repetitionen à drei Messungen (als Messung 1, 2 und 3 festgehalten) pro Befestigungsmethode. Schlussendlich lagen pro Pferd 18 Sets (Schritt und Trab) von Messungen jeweils als "straps-on" und "glved-on"-Methode vor. Das System der Trägheitssensoren beinhaltet die Software Poseidon $9^{\text {TM }}$, welche die zeitlichen und räumlichen Messdaten auswertet. Die beschreibende Datenanalyse wurde mittels einer kommerziell erhältlichen Software NCSS 10 durchgeführt. Mit dieser wurden repeated measures ANOVAs erstellt. 